\title{
Effect of Telfaira occidentalis Leaf Extract on Packed Cell Volume in Rats with Malaria-induced Anaemia
}

\author{
Chris O. Ikese ${ }^{a, \star}\left(\mathbb{D} \S\right.$, Simon T. Ubwa ${ }^{a}$, Sunday O. Adoga ${ }^{a}$, Steven I. Audu, \\ Mathias I. Kuleve ${ }^{d}$, Faith O. Okita ${ }^{c}$ and Amodu Okoh ${ }^{a}$ \\ ${ }^{a}$ Department of Chemistry, Benue State University, Makurdi 970222, Nigeria. \\ ${ }^{b}$ Department of Chemistry, Nasarawa State University, Keffi 961101, Nigeria. \\ ${ }^{c}$ Department of Biological Sciences, Benue State University, Makurdi 970222, Nigeria. \\ ${ }^{d}$ Department of Medical Microbiology and Parasitology, Benue State University, Makurdi 970222, Nigeria.
}

Received 31 October 2019, revised 24 February 2020, accepted 25 February 2020.

\section{ABSTRACT}

The bioactive ingredients in most malarial drugs only reduce plasmodium load during chemotherapy. No anti-malarial drug replenishes the red blood cells destroyed by Plasmodium. This creates a need to incorporate bioactive components with haematinic property in malaria therapy. This study aimed to assess the effect of $T$. occidentalis leaf extract on packed cell volume (PCV) of rats with malaria-induced anaemia. Anaemia was induced in the rats by inoculating them with Plasmodium berghei. The effect of the plant extract on the PCV of the rats was determined alongside a negative and a positive control. Also, the effect of varying doses of the extract on PCV of the rats was determined. T. occidentalis leaf extract produced a $22 \%$ increase in the post-inoculation PCV of rats. The negative and positive control groups showed a $37 \%$ and $25 \%$ decrease, respectively, in PCV. Also, PCV increased with increase in extract dose administered.

\section{KEYWORDS}

Malaria, Telfaira occidentalis, malaria-induced anaemia, packed cell volume, rats.

\section{Introduction}

Malaria has remained a major public health challenge worldwide especially in the tropical parts of Africa. ${ }^{1,2}$ It is an infectious disease caused by Plasmodium species and is characterized by fever, headache, sweating, anaemia, occasional seizures, and other related symptoms. ${ }^{3}$ In tropical Africa, most cases of malaria are due to Plasmodium falciparium. ${ }^{4}$ When malaria is not treated promptly it can lead to anaemia and maternal death in pregnant women. ${ }^{3}$ The disease impacts negatively on the learning abilities of its victim, especially children and reduces the working abilities of affected individuals. , $^{1,5}$

Anaemia is a common complication associated with malaria. ${ }^{5}$ Depending on the severity, its symptoms may include pale skin, fatigue, weakness, breathlessness, frequent headache and others. ${ }^{6}$

There are several types of anaemia. Anaemia may be aplastic if there is a production defect in the red blood cells (RBC), megaloblastic - if there is a maturation defect of RBC, thalassaemic - if there is a genetic defect of the haemoglobin, haemolytic - if there is an excessive physical loss of $\mathrm{RBC}^{7}$ just to mention a few. This study addresses the haemolytic anaemia induced by malaria. Some of the chemotherapeutic drugs available for the treatment of malaria such as Primaquine and tafenoquine have been reported to cause haemolytic anaemia in people with glucose-6-phosphate dehydrogenase deficiency. ${ }^{8}$ Treatment for haemolytic anaemia may vary depending on the cause of the illness and it may include blood transfusions, corticosteroid medicines, rituximab ${ }^{9}$ among others.

The role of Artemisinin in malaria treatment is to reduce the parasite load during treatment, as it is not anti-anaemic. The plasmodium life cycle involves the rupture of erythrocytes to

* To whom correspondence should be addressed.

E-mail: ichris@ bsum.edu.ng release merozoites which reinfect other $\mathrm{RBC}$ in repeated cycles, causing continuous red cell lysis so that malaria-induced anaemia ensues. Studies have shown that excessive destruction of RBC during a bout of malaria and even during treatment causes mild to severe anaemia, a situation which makes recuperation from malaria even more difficult and stressful on the patient. Reduction of the RBC leads to a decrease in the capacity to work, increased maternal and child mortality and impaired neurocognitive function in children. ${ }^{10}$ This is perhaps a justification for some of the studies ${ }^{11}$ conducted to rapidly raise the levels of RBC in anaemic persons.

Telfairia occidentalis is cultivated in west Africa ${ }^{12,13}$ and commonly known as fluted pumpkin or Ugwu in Nigeria. ${ }^{14}$ Several studies ${ }^{15-25}$ have been carried out on the therapeutic potentials of T. occidentalis. One study ${ }^{26}$ reported the effect of diet formulations of the air-dried leaves of T. occidentalis on haematological parameters in rats. However, it is not known whether or not the aqueous extract of the leaves will have any significant effects on haematological indices. ${ }^{27} \mathrm{PCV}$ is the volume percentage of red blood cells in the blood and the value depends on the number and size of red blood cells. ${ }^{28}$ An abnormally low PCV may be indicative of anaemia. This study aims at evaluating the effect of $T$. occidentalis aqueous leaf extract on PCV in rats with malaria-induced anaemia and the effect of varying dosage of the extract on the PCV.

\section{Experimental}

\subsection{Materials and Sample Preparation}

Fresh leaves of T. occidentalis were collected from a vegetable garden in Kokona, Nasarawa state in Nigeria and authenticated by a botanist in the national institute of pharmaceutical research and development (NIPRD). 
The leaves were washed, rinsed with distilled water and airdried. $250 \mathrm{~g}$ of the air-dried leaves were macerated in distilled water for $24 \mathrm{~h}$ and then filtered. The filtrate was further concentrated at $85^{\circ} \mathrm{C}$ using a hot water bath to give T. occidentalis leaf extract.

Four grams ( $4 \mathrm{~g}$ ) of air-dried T. occidentalis leave sample was pulverized in a porcelain mortar and $2 \mathrm{~g}$ of the ground sample was ashed in a muffle furnace. The resulting ash was then digested using concentrated $\mathrm{HCl}$. The solution was then analyzed in duplicates for the levels of $\mathrm{Fe}, \mathrm{Ca}, \mathrm{Mg}, \mathrm{Zn}, \mathrm{K}, \mathrm{Na}$ and $\mathrm{Pb}$ using an atomic absorption spectrophotometer (SOLAR 929 Unicam A.A. Spectrophotometer, UK) and the mean values reported.

\subsection{Effect of Telfairia occidentalis Leaf Extract on PCV in Rats with Malaria-induced Anaemia}

Thirty-five (35) winstar albino rats were used as animal models in this study. The rats were divided into 7 groups, each group comprising of 5 rats. Groups 1, 2 and 3 served as the negative control, positive control and experimental group, respectively, while groups 4, 5, 6 and 7 served as dosage group. The mean baseline PCV (pre-inoculation PCV) of all groups were measured with a microhematocrit and recorded. All groups were then inoculated with $P$. berghei and the parasite was allowed to fully develop in the hosts before commencing measurement of post-inoculation PCV at intervals of $24 \mathrm{~h}$. The change in PCV was calculated for groups 1, 2 and 3 using Equation (1).

$$
\text { Change in PCV }=\frac{\text { PCV on day } 5-\mathrm{PCV} \text { on day } 1}{\text { PCV on day } 1} \times 100 \%
$$

Two milligrams per kilogram body weight $(2 \mathrm{mg} / \mathrm{kg}$ ) artesunate was dissolved in distilled water and administered to groups 2 and 3 followed by the administration of $200 \mathrm{mg} / \mathrm{kg}$ T. occidentalis extract only to the experimental group. The mean post-inoculation PCV was measured in duplicates for five consecutive days and statistically compared using t-test.

\subsection{Effect of Telfaria occidentalis Leaf Extract Dosage on PCV in Rats with Malaria-induced Anaemia}

The experimental procedure described above was repeated for groups 4 ,5, 6 and 7 except that no control group was required and varied dosages of the aqueous extract was used. The aqueous extract doses administered were 100, 200, 300, and $400 \mathrm{mg} / \mathrm{kg}$ to the groups, respectively. All groups were monitored closely and their PCVs determined in duplicates and the mean recorded.

\section{Results}

The mineral composition of T. occidentalis aqueous leaf extract is presented in Table 1 . The abundance of the mineral elements is in the order; $\mathrm{K}>\mathrm{Fe}>\mathrm{Ca}>\mathrm{Mg}>\mathrm{Zn}>\mathrm{Na}>\mathrm{Pb}$.

The baseline PCV, as well as the PCV of rats after administering T. occidentalis aqueous leaf extract (post-inoculation PCV) are presented in Table 2, where it can be seen that the postinoculation PCV in the negative and positive control groups declined progressively from day 1 to day 5 (i.e. from 39.4 to $25.0 \%$ and from 40.8 to $30.6 \%$, respectively). Also, the postinoculation PCV of the experimental group (group administered with the plant extract), increased progressively from day 1 to day 5 (from 42.0 to $51.2 \%$ ).

The effect of varying doses of the extract on PCV in rats with malaria-induced anaemia is presented in Table 3 . The baseline PCV of groups administered with 100, 200, 300 and $400 \mathrm{mg} / \mathrm{kg}$ $(51.00,50.80,52.20$ and $51.20 \%$, respectively) increased to 43.20 , $51.20,52.60$ and $53.80 \%$, respectively, on day 5 .

\section{Discussion}

Although the concentration of $\mathrm{K}$ in the extract is highest, $\mathrm{Fe}$ is the element of erythropoietic importance as it is a crucial component of the haemoglobin needed to form red blood cells in bone marrow. ${ }^{14}$ Such a high level of Fe in the extract, is indicative of its potential ability to boost Fe levels in the experimental subjects ${ }^{29}$ and hence RBC production in animal subjects with malariainduced anaemia. This observation may have been responsible for the marked increase in PCV of rats administered with the extract as seen in Table 2. This is consistent with reports that iron is needed for the formation of haemoglobin, ${ }^{14}$ which aid the formation of RBCs.

As seen in Table 2, post-inoculation PCV in both the negative and positive control groups continued to decline progressively from day 1 to 5 . At day 5, both control groups had shown a $37 \%$ and $25 \%$ decline in post-inoculation PCV, respectively. Conversely, the post-inoculation PCV of the experimental group increased progressively from day 1 to day 5, showing that the extract produced a $22 \%$ increase in post-inoculation PCV on day 5 compared with day 1 . Also, in the experimental group, the extract elevated the post-inoculation PCV on day 5 , to a value

Table 1 Mineral content of Telfaira occidentalis aqueous leaf extract.

\begin{tabular}{lccccccc}
\hline Mineral & $\mathrm{Fe}$ & $\mathrm{Ca}$ & $\mathrm{Mg}$ & $\mathrm{Zn}$ & $\mathrm{K}$ & $\mathrm{Na}$ & $\mathrm{Pb}$ \\
\hline Concentration (ppm) & $7.403 \pm 0.030$ & $4.927 \pm 0.010$ & $3.000 \pm 0.001$ & $1.950 \pm 0.011$ & $41.500 \pm 0.002$ & $0.950 \pm 0.021$ & $0.091 \pm 0.001$ \\
\hline
\end{tabular}

KEY: Results are presented as mean \pm standard deviations of duplicate determinations $(n=2)$.

Table 2 Baseline and PCV in rats following treatment with Telfaira occidentalis aqueous leaf extract.

\begin{tabular}{|c|c|c|c|c|c|c|c|}
\hline \multirow[t]{2}{*}{ Group } & \multirow{2}{*}{$\frac{\text { Baseline PCV }(\%)}{\text { Day } 0}$} & \multicolumn{5}{|c|}{ Post-inoculation PCV (\%) } & \multirow[t]{2}{*}{ Change in PCV (\%) } \\
\hline & & Day 1 & Day 2 & Day 3 & Day 4 & Day 5 & \\
\hline 1 & $52.20 \pm 2.16$ & $39.40^{\mathrm{a}} \pm 1.14$ & $36.00^{a} \pm 3.03$ & $33.40^{a} \pm 1.34$ & $29.00^{\mathrm{a}} \pm 1.36$ & $25.00^{\mathrm{a}} \pm 0.70$ & $-37 \%$ \\
\hline 2 & $52.00 \pm 4.30$ & $40.80^{\mathrm{a}} \pm 0.84$ & $38.00^{\mathrm{a}} \pm 1.67$ & $36.50^{\mathrm{a}} \pm 1.57$ & $34.00^{\mathrm{a}} \pm 1.58$ & $30.60^{\mathrm{a}} \pm 1.14$ & $-25 \%$ \\
\hline 3 & $50.80 \pm 2.86$ & $42.00^{\mathrm{a}} \pm 1.64$ & $44.80^{\mathrm{b}} \pm 1.30$ & $47.00^{\mathrm{c}} \pm 1.52$ & $50.00^{\mathrm{c}} \pm 1.22$ & $51.20^{c} \pm 1.48$ & $+22 \%$ \\
\hline
\end{tabular}

KEY: Results are presented as mean \pm standard deviation of duplicate determinations $(n=5)$.

Group 1 (Negative control) $=$ inoculated with P. berghei + standard rat feed + potable water.

Group 2 (Positive control) = inoculated with P. berghei + arthesunate anti-malaria + standard rat feed + potable .water

Group $3($ Experimental $)=$ inoculated with P. berghei + arthesunate anti-malaria dosage + standard rat feed + Potable water + T. occidentalis $200 \mathrm{mg} / \mathrm{kg}$.

Means with identical superscripts within a row are not significantly different at $P=0.05$. 
Table 3 Effect of extract dosage on PCV in rats with malaria-induced anaemia.

\begin{tabular}{|c|c|c|c|c|c|c|}
\hline \multirow[t]{2}{*}{ Group } & \multirow{2}{*}{$\frac{\text { Baseline PCV }(\%)}{\text { Day } 0}$} & \multicolumn{5}{|c|}{ Post-inoculation PCV/\% } \\
\hline & & Day 1 & Day 2 & Day 3 & Day 4 & Day 5 \\
\hline 4 & $51.00 \pm 1.00$ & $40.00 \pm 2.45$ & $40.70 \pm 2.36$ & $42.00 \pm 2.16$ & $42.50 \pm 1.73$ & $43.20 \pm 1.89$ \\
\hline 5 & $50.80 \pm 2.86$ & $42.00 \pm 1.64$ & $44.80 \pm 1.30$ & $47.10 \pm 1.52$ & $50.00 \pm 1.22$ & $51.20 \pm 1.48$ \\
\hline 6 & $52.20 \pm 3.34$ & $42.50 \pm 1.82$ & $45.00 \pm 2.28$ & $49.00 \pm 1.64$ & $51.40 \pm 1.67$ & $52.60 \pm 1.52$ \\
\hline 7 & $51.20 \pm 6.42$ & $41.60 \pm 3.74$ & $45.30 \pm 3.03$ & $49.20 \pm 2.70$ & $52.00 \pm 2.86$ & $53.80 \pm 1.30$ \\
\hline
\end{tabular}

KEY: Results are mean \pm standard deviations of duplicate determinations $(n=5)$.

Group $4=$ P. berghei + arthesunate anti-malaria dosage + standard rat feed + potable water + T. occidentalis $100 \mathrm{mg} / \mathrm{kg}$.

Group $5=$ P. berghei + arthesunate anti-malaria dosage + standard rat feed + potable water + T. occidentalis $200 \mathrm{mg} / \mathrm{kg}$.

Group $6=$ P. berghei + arthesunate anti-malaria dosage + standard rat feed + potable water + T. occidentalis $300 \mathrm{mg} / \mathrm{kg}$

Group $7=$ P. berghei + arthesunate anti-malaria dosage + standard rat feed + potable water + T. occidentalis $400 \mathrm{mg} / \mathrm{kg}$.

that is $0.8 \%$ higher than the baseline PCV. The observed $22 \%$ increase in post-inoculation PCV is higher than the $13 \%$ increase in PCV reported by Toyin et al..$^{27}$ following a 7 day feeding trial in a related study. Thus, it can be said that T. occidentalis extract increases the PCV of rats with malaria-induced anaemia. A statistical comparison of the mean PCVs of the control and experimental groups on day 5 (i.e $30.0 \%$ and $51.0 \%$, respectively) by t-test showed that the difference between both means were significantly different at $P=0.05$ and d.f. 49 , as the calculated $t$-value (20.33) was greater than the critical t-value (2.303).

In Table 3, the post-inoculation PCV of all dosage groups increased progressively through day 1 to 5 ; however, these increases were only marginal when compared to respective baseline values. In any case, by day 5 , the recorded PCVs were found to be in the order; Group $7>$ Group $6>$ Group $5>$ Group 4, thus implying that the extract's ability to increase PCV in rats with malaria-induced anaemia is dose-dependent.

\section{Conclusion}

The results of this study indicate that the aqueous extracts of the leaves of T. occidentalis may boost RBCs production during infection with Plasmodium. The extracts may have a direct effect on the body system that produces blood cells and contains constituent(s) that could stimulate the formation and secretion of erythropoietin and hematopoietic growth stem cells. This suggests that the aqueous extracts of the leaf of this plant possess haematinic properties, which is potent in boosting and enhancing PCV of a rat with malaria-induced anaemia.

\section{Acknowledgement}

The researchers are grateful to the Benue State University, Makurdi and the National Institute of Pharmaceutical Research and Development (NIPRD) Abuja, for providing the laboratory space and equipment for this research.

\section{${ }^{s}$ ORCID ID}

\section{C.O. Ikese: (iD) orcid.org/0000-0002-6657-685X}

\section{Author Contribution}

Conceptualization, Chris O. Ikese; formal analysis, Chris O. Ikese; funding acquisition, Chris O. Ikese; methodology, Mathias I. Kuleve and Amodu Okoh; validation, Simon T. Ubwa; writing - original draft, Chris O. Ikese; writing - review \& editing, Simon T. Ubwa, Sunday O. Adoga, Steven I. Audu, Mathias I. Kuleve and Faith O. Okita.

\section{Funding}

All components of this research work was funded entirely by the Tertiary education trust fund (TETFUND) under its institution-based research grant (IBR)

\section{Conflict of Interest}

The authors declare no conflict of interest.

\section{References}

1 WHO (World Health Organization), 2016 World Malaria Report Summary, WHO, Geneva, Switzerland, 2016, 61, 1-17.

2 M.B. Richard, J.L. Lesetja, I. Michelle, D.K. Setshaba, L. and Dustin, C.H. Heinrich, Anti-trypanosomal and antimalarial properties of tetralone derivatives and structurally related benzocycloalkanones, Medicina, 2019, 55, 206-216.

3 J. Schantz-Dunn, M. Nawal and M.D. Nour, Malaria and pregnancy: a global health perspective, Rev. Obstet. Gynecol., 2009, 2(3), 186-192

4 The World Health Report 2002: Reducing Risks, Promoting Healthy Life, World Health Organization, Geneva.

5 J.L. Kurtzhals, O. Rodrigue, M. Addae, J.O. Commey, F.K. Nrumah and L. Hviid, Reversible suppression of bone marrow response to erythroprotein in Plasmodium falciparum malaria, Brit. J. Haem., 1996, 97, 169-174.

6 O. Ayodotun and M. Olugbenga, Severe malaria anaemia in children, Anaemia. InTech., 2012, 18, 284-312.

7 N. Soundarya and P. Suganthi, A review on anaemia - types, causes, symptoms and their treatments, J. Sci. \& Tech. Invest., 2016, 1(1), 10-17.

8 M.D. Gershman, E.S. Jentes, R.J. Stoney, K.R. Tan and P.M. Arguin (Malaria) CDC Yellow Book 2020, Yellow Fever Vaccine \& Malaria Prophylaxis Information, by Country. p. 164.

9 H. Birgens, H. Frederiksen, H.C. Hasselbalch, I.H. Rasmussen, O.J. Nielsen and L. Kjeldsen, A phase III randomised trial comparing glucocorticoid monotherapy versus glucocorticoid and rituximab in patients with autoimmune haemolytic anaemia, Brit. J. Haem., 2013, 163(3), 393-399.

10 NIAID (National Institute of Allergy and Infectious Diseases), Understanding Malaria: Fighting an Ancient Scourge. U.S. Department of Health and Human Services, 2007, 71, 1-19.

11 S.J. Dudrick, J.J. O’Donnel, D.P. Raleigh, R.G. Matheny and S.P. Unkel, Rapid restoration of red blood cell mass in severely anemic surgical patients who refuse transfusion, Arch. Surg., 1985, 120, 721-727.

12 H.M. Burkett, The results of plants of West Africa, Royal Bot. Gard. Kews. Eng., 1968, 1, 603-604.

13 G.I. Badifu, M.A. Akpapunan and V.M. Mgbemere, The fate of betacarotene in processed leaves of fluted pumpkin, a popular vegetable in Nigerian diet plant foods, Hum. Nutri., 1995, 48, 141-147.

14 F. Hamlin and G.O. Latunde-Dada, Iron bioavailability from a tropical leafy vegetable in anaemic mice, Nutr. Metab., 2011, 8, 19 . DOI: $10.1186 / 1743-7075-8-9$

15 M.F. Olaniyan and A. Adeleke, A study of the effect of pumpkin (Ugwu - Telfaria occidentalis), milk and egg mixture in the treatment of anaemic pregnant women in rural area, Afri. J. Trad. Comp. Alt. Med., 2005, 2, 269-273.

16 A.A. Osuntoki and A.O. Sanusi, Telfaria occidentalis extract stabilizes human erythrocyte membrane, Nig. Q. J. Hosp. Med., 2007, 17, 116-119.

17 S. Idris, Compositional studies of Telfairia occidentalis leaves, Amer. J. Chem., 2011, 2, 56-59.

18 C.E. Ekpenyong, E.E. Akpan and N.S. Udoh, Phytochemistry and toxicity studies of Telfairia occidentalis aqueous leaves extract on liver biochemical indices in winstar rat, Am. J. Med. Med. Sci., 2012, 5, 103-110. 
19 A.A. Kayode and O.T. Kayode, Some medicinal value of Telfairia occidentalis: a review, Ameri. J. Biochem. Mol. Bio., 2011, 1, 30-38.

20 E.I. Obeagu, I.M. Chikelu, T.N. Obarezi, B.N. Ogbuabor and Q.B. Anaebo, Haematological effects of fluted pumpkin (Telfairia occidentalis) leaves in rats, Int. J. Life Sci. Biotech. Pharm. Res., 2014, 3 2250-3137.

21 F.S. Oluwole, A.O. Falade and O.O. Ogundipe, Anti-inflammatory effect of some common Nigerian vegetables, Nig. J. Physiol. Sci., 2003, 18, 35-38.

22 O.I. Ajayi, T.C. Ajayi, E.D. Omokaro and N.K. Halim. Erythropoietic value of Telfairia occidentalis on rabbit: a preliminary study, Nig. J. Physiol. Sci., 2000, 16, 1-3.

23 A.A. Adedapo, O.A. Dina, A.B. Saba and O.D. Oladipo. Evaluation of Telfairia occidentalis and Sorghum bicolor extracts as potent haematinics in domestic rabbits, Nig. J. Animal Prod., 2002, 29, 88-93.

24 C.S. Odoemena and J.P. Essein. Antibacterial activity of the root extract of Telfairia occidentalis, West Afr. J. Biol. Appl. Chem., 1995, 40, $1-4$.

25 O.A. Dina, A.A. Adedapo, O.P. Oyinloye and A.B. Saba, Effect of Telfaria occidentalis extract on experimentally induced anaemia in domestic rabbits, Afr. J. Biomed. Res., 2000, 13, 181-183.

26 A. Alada, The haematological effects of Telfairia occidentalis diet preparation, Afr. J. Biomed. Res., 2000, 3, 185-186.

27 M.S. Toyin, A.O. Luqman and A.O. Wahab, Aqueous extract of Telfairia occidentalis leaves reduces blood sugar and increases haematological and reproductive indices in male rats, Afr. J. Biotech., 2008, 14, 2299-2303.

28 Hematocrit. MedlinePlus Medical Encyclopedia. https://medlineplus.gov (retrieved 5 February 2020).

29 J.O. Agbede, M. Adegbenro, G.E. Onibi, C. Oboh and V.A. Aletor, Nutritive evaluation of Telfairia occidentalis leaf protein concentrate in infant foods, Afr. J. Biotech., 2008, 7, 2721-2727. 